Methods A nurse-led coordination team based at the hospice arranges rapid packages of care and equipment and acts as a helpline for patients, families and professionals. An end of life community nurse provides face-to-face support to patients and families and a link to community nurses. Marie Curie health and personal care assistants offer specialised care. OPM have been commissioned to evaluate the model.

Results The service supported over 400 patients in its first year. The independent evaluation found patients and families felt supported to stay at home, and professionals noticed an improvement in the quality of care and the speed of organising care packages. Professionals report they have saved time on administration. Challenges included achieving buy-in from other providers and a lack of capacity to deliver care packages among care agencies.

Conclusions The care coordination model has improved the quality of care in the CCG and enabled more people to die at home. There is evidence admissions are being avoided and hospital discharges are faster. Now in our second year of the pilot, we are working with partners using evidence captured in the evaluation to shape the future model and hopefully secure ongoing funding.

\section{0-15 VOLUNTEER BEFRIENDING SERVICES: LESSONS FROM A RANDOMISED CONTROLLED TRIAL ON WHO ACCESSES THESE SERVICES AND HOW TO MAXIMISE SERVICE IMPACT}

${ }^{1}$ Catherine Walshe, ${ }^{1}$ Steven Dodd, ${ }^{1}$ Guillermo Perez Algorta, ${ }^{2}$ Matthew Hill, ${ }^{2}$ Nick Ockenden, ${ }^{1}$ Sheila Payne, ${ }^{1}$ Nancy Preston. ${ }^{1}$ International Observatory on End of Life Care, Lancaster, UK; ${ }^{2}$ Institute for Volunteering Research, NCVO, London, UK

\subsection{6/bmjspcare-2016-001245.15}

Background Volunteer provided befriending or good neighbour services are an increasingly common element of hospice provision. However little is known about who accesses such services, nor their impact. The ELSA study is a large trial of volunteer befriending services across England, with an aim of evaluating the effectiveness of receiving care.

Aim To report data on who was referred to and used the befriending services provided as part of this trial.

Methods A wait-list controlled trial (ELSA) with nested qualitative case studies, with patients randomly allocated to intervention (immediate receipt of volunteering intervention) or wait list arm (four week wait for intervention). Patients (estimated to be in their last year of life) referred to volunteer befriending services across 11 end of life care providers in England. Trial data were collected at baseline, 4, 8 (12) weeks to explore quality of life as our primary outcome, with loneliness and social support as secondary outcomes. Baseline data were collected on personal characteristics and social networks. Trial registered: ISRCTN 12929812

Results Service referrals $(n=369)$ resulted in 195 people entering the study. Patients mean age 72 years, $61 \%$ female, $84 \%$ retired, 58\% living alone, 90\% white ethnicity, 50\% with cancer. No significant differences on quality of life at baseline were observed between genders, but as age increases, scores on social, psychological and environmental sub scales worsen $(p s .<0.01)$. Age and living alone were significant predictors of lower environment scores $(p s$. $<0.01)$. Quality of life scores were lower than those of comparator populations.

Conclusion This study is the first to examine volunteer befriending in a trial context, and describe the characteristics of those receiving care. Services appear appropriately targeted to vulnerable older adults who live alone, and potentially accessed by a wider range of people than other hospice services. Funded by the UK Cabinet Office. See also poster presentation \#205.

\section{0-16 DEVELOPMENT OF A MOCK PEER REVIEW MODEL}

${ }^{1}$ Judith Park, ${ }^{1}$ Mark Harrington, ${ }^{2}$ Ruth Gretton. 'St Luke's Hospice, Sheffield, UK; ${ }^{2}$ Dorothy House Hospice Care, Bradford on Avon, UK

\subsection{6/bmjspcare-2016-001245.16}

Background Following one hospice sharing their experiences of piloting the Care Quality Commission's (CQC) new inspection model, two hospices have been working in partnership to increase awareness and understanding about what CQC inspections entail, to better prepare hospices for an inspection. Their discussions led to the decision that undertaking peer reviews could be beneficial.

Aim To develop and undertake a peer review of another hospice's services to increase staff awareness and understanding about what CQC inspections entail and add value to their practices.

Methods To ensure the visit generated useful information it followed the style of a real life inspection and considered the five key lines of enquiry.

The visiting team undertook a review of available information on the hospice and developed structured question sets.

An unannounced visit was undertaken to test all hospice procedures and gain an overview of standards. The team held discussions with executives, managers, staff, volunteers, patients, carers and relatives, observed practices both on site and out in the community, and assessed documentation.

A report summarising the findings and suggestions for improvements was also produced.

Results Both hospices felt the experience was extremely valuable and rewarding and it increased staff understanding and awareness of what CQC inspections entail to ensure better preparation about what to expect.

The visit highlighted areas not currently on the hospice's radar and provided the opportunity to implement changes before an inspection. It also enabled the hospices to share experiences, good practices, tools and documents.

Interpretation/conclusions Mock peer review visits are a positive opportunity to describe and demonstrate staff and hospice strengths and development plans, and implementing a regional peer review programme would better prepare hospices for CQC inspections, enable identification of potential issues and encourage sharing of working practices that could improve both safety and effectiveness of end-of-life care.

\section{Conference Papers 5}

\section{0-17 INVESTING IN THE FUTURE OF HOSPICE CARE}

Julia O'Neill. Hospice Care for Burnley and Pendle, Burnley, UK

10.1136/bmjspcare-2016-001245.17

Pendleside Hospice is keen to support young people in our community, in order to promote accessibility and to advance our workforce strategy. We recognise that young people are effective ambassadors for the hospice.

In 2015/16 we introduced; 
1. An apprenticeship programme

2. A work experience scheme.

Apprenticeship programme

The apprentices work in three different areas of the hospice;

- Day Services - social care student

- Clinical Administration - student administrator

- Kitchen and Domestic Service - catering student.

All apprentices work alongside experienced staff to gain jobspecific skills. Learning is supplemented by training provided by local colleges, as they work towards nationally recognised qualifications.

The apprentices bring energy and innovation to the hospice, which is appreciated by our patients. It is rewarding to know that we are providing practical skills, experience and knowledge in their chosen careers that will help them to develop both personally and professionally.

Work experience scheme Pendleside Hospice has introduced a structured approach to work experience aimed at young people interested in a career in health and social care. This consists of learning forums and work experience in our three clinical areas. For those who hope to undertake medical training, there is the opportunity to shadow a member of our medical team for the day.

Learning forum workshops;

- Overview of hospice and palliative care

- Death, dying and bereavement

- Ethical decision making in palliative care.

The workshops are interactive and it was interesting to hear the young person's view of death and dying, which will be used to help map service development.

This new initiative allows Pendleside to respond to the large volume of work experience requests we receive. It has provided many young ambassadors in our community championing the work of the hospice.

\section{0-18 STEPPING INTO A NEW FUTURE - OUR JOURNEY INTO DELIVERING NURSE-LED CARE}

Jackie Whiller. Earl Mountbatten Hospice, Newport, UK

\subsection{6/bmjspcare-2016-001245.18}

Introduction The introduction of a nurse-led model of care within our hospice is at our fingertips. Traditionally we have always used a consultant-led model.

As we move into the future and open our doors to a wider population needing palliative care services, we need to consider our options, ensuring we are fit for the future. Introducing nurseled care provides a valuable resource for patients and families.

Aims of project

- Pilot the delivery of nurse-led care

- Build the potential for nursing leadership

- Establish advanced practice in inpatient care

- Change and challenge traditional practices

- Effective and efficient use of palliative care consultant time.

Evidence and experience to date Since November 2015 we have been piloting a nurse-led model of care. Patients are transferred into the nurse- led model of care with their consent, providing a seamless and holistic patient centred service. Anecdotal evidence from relatives suggests that this is a valued and useful service.
Patient experience surveys have provided evidence that there has been no deterioration in the satisfaction expressed in the quality and efficiency of care received. The expected challenge by the inpatient nursing team in delivering a new model of care has not been evident.

Developments for the future

- Clear programme in place for the sustainable delivery of advanced nursing practice in the inpatient setting

- Development of robust tools to measure and analyse the impact on nurse-led care for the individual, team and organisation

- Establish if nurse-led care is a viable alternative to consultantled care

- Development of allied health professional-led care.

Conclusion Our experience to date has identified that the delivery of nurse-led care within our organisation provides an alternative model that releases the potential for nurses and doctors alike.

\section{0-19 RESEARCH ACTIVE HOSPICES: THE POTENTIAL OF PEOPLE AND PARTNERSHIPS}

Sarah Russell, Melanie Hodson. Hospice UK, London, UK

\subsection{6/bmjspcare-2016-001245.19}

Background Supporting hospices to be research active is a strategic objective of Hospice UK following the publication of Research in palliative care: can hospices afford not to be involved? (Payne et al., 2013).

Aims To understand the needs, concerns and potential solutions from the hospice, academic, NHS research, clinical community and other stakeholders for hospices to be research active.

Methods November 2015 to February 2016 informal mapping was carried out with 34 stakeholders (data set 1). May to June 2016, two stakeholder meetings with 110 participants (data set 2) and a Survey Monkey questionnaire with over 100 responses (data set 3). May 2016 a \#whywedoresearch Twitter chat on hospice research with@researchospice (data set 4).

Results Data driven thematic analysis of the four data sets reported in three domains (needs, concerns and potential solutions). The three domains were also set within a micro (individual), meso (team or organisational) and macro (regional or national) context.

\begin{tabular}{|c|c|}
\hline Needs & Concerns \\
\hline Funding & Organisational culture \\
\hline Staff capacity & Indemnity variability \\
\hline Hospice infrastructure & NHS R\&D relationships and NHS site definition \\
\hline $\begin{array}{l}\text { Research education and } \\
\text { experience }\end{array}$ & $\begin{array}{l}\text { Gap between hospices who can/cannot be research } \\
\text { active }\end{array}$ \\
\hline To map hospice research activity & $\begin{array}{l}\text { Difficulty in recruiting to studies } \\
\text { Potential solutions }\end{array}$ \\
\hline \multicolumn{2}{|c|}{ Relationships with universities, CRN, NIHR, CRN and NHS R\&D departments } \\
\hline \multicolumn{2}{|c|}{ Local, regional, national groups and networking } \\
\hline \multicolumn{2}{|l|}{ Named and/or shared posts } \\
\hline \multicolumn{2}{|c|}{ National Hospice Research Framework } \\
\hline \multicolumn{2}{|l|}{ Education pathway } \\
\hline \multicolumn{2}{|c|}{ Hospice UK as a conduit for resources and relationships } \\
\hline \multicolumn{2}{|c|}{ Map activity or readiness (but more discussion and detail needed) } \\
\hline
\end{tabular}

